\title{
Liver Transplantation for Non-Resectable Liver Metastases from Colorectal Cancer: A Systematic Review and Meta-Analysis
}

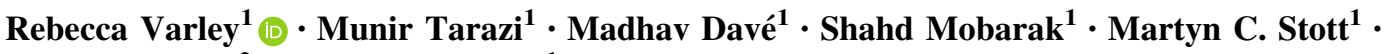 \\ Minas Baltatzis ${ }^{2} \cdot$ Thomas Satyadas $^{1}$
}

Accepted: 10 July 2021 / Published online: 28 July 2021

(C) The Author(s) 2021

\begin{abstract}
Backgrounds Colorectal liver metastases were historically considered a contraindication to liver transplantation, but dismal outcomes for those with metastatic colorectal cancer and advancements in liver transplantation (LT) have led to a renewed interest in the topic. We aim to compare the current evidence for liver transplantation for nonresectable colorectal liver metastases (NRCLM) with the current standard treatment of palliative chemotherapy. Methods A systematic review and meta-analysis of proportions was conducted following screening of MEDLINE, EMBASE, SCOPUS and CENTRAL for studies reporting liver transplantation for colorectal liver metastases. Postoperative outcomes measured included one-, three- and five-year survival, overall survival, disease-free survival and complication rate.

Results Three non-randomised studies met the inclusion criteria, reporting a total of 48 patients receiving LT for NRCLM. Survival at one-, three- and five-years was $83.3-100 \%, 58.3-80 \%$ and $50-80 \%$, respectively, with no significant difference detected $(p=0.22, p=0.48, p=0.26)$. Disease-free survival was $35-56 \%$ with the most common site of recurrence being lung. Thirteen out of fourteen deaths were due to disease recurrence.

Conclusion Although current evidence suggests a survival benefit conferred by LT in NRCLM compared to palliative chemotherapy, the ethical implications of organ availability and allocation demand rigorous justification. Concomitant improvements in the management of patients following liver resection and of palliative chemotherapy regimens is paramount.
\end{abstract}

Rebecca Varley and Munir Tarazi equally contributed and are joint first coauthors.

\section{Munir Tarazi}

munirtarazi@rcsi.ie

1 Department of Hepato-Pancreato-Biliary Surgery, Manchester Royal Infirmary, Manchester University NHS Foundation Trust, Oxford Road, Manchester M13 9WL, UK

2 Department of Upper GI Surgery, Salford Royal Foundation Trust, Salford, UK

\section{Introduction}

Colorectal cancer (CRC) is the third most common cancer and is responsible for one in four cancer deaths worldwide [1]. 40-50\% of patients will develop secondary liver metastases, the presence of which reduces overall survival by a factor of nine [2]. The incidence of CRC is increasing in younger patients who are more likely to present with or develop liver metastases [3].

Liver resection with neoadjuvant and adjuvant chemotherapy is the gold standard for CRLM, however up to $80 \%$ of cases are non-resectable at presentation. Nonresectable CRLM (NRCLM) treated with palliative chemotherapy has a five-year survival of less than $10 \%$ 
$[4,5]$. Of the $20-40 \%$ who are eligible for a liver resection [2], the median 5-year survival after resection is $38 \%$ (16-74\%) and $40-75 \%$ of these patients will develop recurrent disease, predominantly in the liver [6].

Colorectal liver metastases (CRLM) were historically considered a contraindication to liver transplantation (LT), with a reported five-year survival of $18 \%$ from 1977 to 1995 [7, 8]. Dismal outcomes for those with unresectable metastatic colorectal cancer have led to a renewed interest in the topic, particularly for patients with liverlimited metastases. The last decade has seen a rapid increase in the number of registered trials and the success of trials reported from Norway has generated great enthusiasm. Despite this, there remains little high-level evidence to support LT for CRLM.

The European Liver Transplant Registry (ELTR) has reported 80,347 liver transplants from 1988-2009 with LT for secondary liver tumours representing $0.5 \%$ of thesethe vast majority being for neuroendocrine tumour (NET) metastases $[9,10]$. Transplantation for primary and secondary liver malignancies is becoming increasingly common, accounting for $12 \%$ of all liver transplants prior to 1997 with a recent increase to $24 \%$ [10].

LT for CRLM was originally abandoned, as the poor initial results could not justify the allocation of a scarce supply of organs. In the intervening period, the demand for LT has increased with only a modest corresponding increase in the donor pool and a high waiting-list mortality worldwide [11].

The aim of this systematic review is to evaluate the available evidence for survival and outcomes in patients with NRCLM who have undergone liver transplantation, compared with palliative chemotherapy.

\section{Materials and methods}

\section{Design}

A systematic review and meta-analysis of proportions was conducted in accordance with the PRISMA standards, registered on PROSPERO (CRD42020212716) with methods established prior to conducting review.

\section{Data sources and search strategy}

Eligible studies were identified from MEDLINE/PubMed, EMBASE, SCOPUS and CENTRAL (The Cochrane Library) with a combination of the following search terms: colorectal/colonic/rectal neoplasm, liver/hepatic metastasis/metastases and liver transplant/transplantation. Reference lists of identified studies were screened manually for relevant citations. In addition, the World Health
Organization International Clinical Trials Registry, ClinicalTrials.gov, ISRCTN Register and PROSPERO were searched to identify ongoing and unpublished studies.

\section{Study selection}

Studies reporting LT for CRLM were included in final analysis. The following strict exclusion criteria were applied: non-English language publication, those including children under 18 years of age, non-human studies, case reports and series containing fewer than five patients, conference abstracts, the use of extended criteria or nonstandard donors, and studies reporting other indications for LT.

Two authors (MT, MD) independently reviewed all studies identified by the search strategy. After removing duplicates, the titles and abstracts of the studies were screened for inclusion using Rayyan software [12]. Where there was uncertainty from the study abstract, the full paper was assessed for relevance. Conflicts were resolved through discussion and involvement of a third author (MS) where necessary.

\section{Data extraction}

Two authors (RV, SM) independently extracted data from the studies. Disagreements were resolved through discussion and where consensus could not be reached, a third independent author (MS) was consulted. Extracted variables included study characteristics, patient demographics, disease and treatment details, outcome measures and follow up. Outcome measures included overall survival, one, three, and five-year survival, post-operative morbidity, 30-day mortality, overall mortality, disease-free survival and disease recurrence.

\section{Assessment of risk of bias}

The assessment of methodological quality and risk of bias was carried out by two independent authors (MT, RV). The Cochrane Risk Of Bias In Non-Randomized Studies-of Interventions (ROBINS-I) tool was utilized.

\section{Data synthesis and statistical analysis}

Data synthesis was done using the software Review Manager (RevMan) [13]. Descriptive analysis was performed of study characteristics, baseline patient demographics, and intervention details. All cohort studies included were noncomparative single arm studies; thus, a meta-analysis of proportions was conducted for data to calculate pooled outcome measures. This statistical analysis was performed using MedCalc for Windows, version 19.0 and was carried 
out using a Freeman-Turkey transformation [14] to calculate weighted summary proportion under the fixed and random effects model [15]. Statistical heterogeneity was assessed using Cochran $\mathrm{Q}$ test $\left(\chi^{2}\right)$ and was further quantified by generating an inconsistency statistic $\left(I^{2}\right)$ for each outcome measure with the threshold for heterogeneity considered present if the $P$ value was $<0.05$ or $I^{2}$ was greater than $50 \%$. Kaplan-Meier curves from all included studies were combined to give overall survival (OS) and disease-free survival (DFS) curves (SPSS software).

\section{Results}

\section{Study selection}

The literature search identified 3442 studies. Duplicates were removed, and 2409 studies were assessed for eligibility. Following abstract screening, 2403 studies were excluded as irrelevant. From the remaining six, three studies met the inclusion criteria and comprise the study population for this systematic review: two prospective cohort studies and one retrospective cohort study reporting a total of 48 patients. (PRISMA flowchart, Fig. 1) [16-18].

\section{Methodological quality of included studies}

The observational studies included varied in sample size, conduct, and reporting of outcomes (Fig. 2). Confounding bias was present in the included studies. The authors were able to measure and attempt to control for known confounders. Selection bias was present in all studies, as selection of participants into the study may have been related to the intervention and outcome. The included studies made reasonable efforts at reducing unintended deviation from interventions to limit attrition bias by performing appropriate analyses. Nevertheless, there remained considerable methodological heterogeneity.

\section{Study characteristics}

The three eligible studies included a total of 48 patients transplanted between 1995 and 2016. One retrospective, multicentre study reported a series from centres in France, Portugal and Switzerland $(n=12)$. Two prospective single-arm studies reported cases from Olso, Norway (SECA-I $(n=21)$ and SECA-II trials $(n=15))$. Study characteristics are outlined in Table 1 . Sources of funding were not reported by any study. All results are reported in the order; Toso et al. [16], Hagness et al. (SECA-I) [17] Dueland et al. (SECA-II) where not otherwise specified [18].

\section{Study participants}

Tosa et al. [16] describe six patients undergoing planned transplantation; detailed selection criteria used were not reported. The remaining six in the study underwent "compassioned" transplantations following surgical complications $(n=3)$ or due to extensive disease burden $(n=3)$. No pre-operative investigation details were described. Eight patients received an mTOR inhibitor.

SECA-I [17] included patients with WHO performance status 0 or 1 , completed radical excision of the primary tumour, minimum of six weeks chemotherapy and absence of extrahepatic disease. Patients were excluded if they had greater than $10 \%$ weight loss, standard contra-indications for LT, or had other malignancies. Pre-operative investigations included computed tomography (CT) of thorax, abdomen and pelvis (TAP), positron emission tomography (PET)/CT, bone scan, repeat CT TAP at time of LT, staging laparotomy if negative CT TAP and included frozen section of lymph nodes in the hepatoduodenal ligament. All patients received sirolimus, mycofenolate mofetil and corticosteroids.

SECA-II [18]: as for SECA-I plus no liver metastasis larger than $10 \mathrm{~cm}$ prior to chemotherapy with at least $10 \%$ response by RECIST criteria, if more than 30 lesions all less than five centimetres $(\mathrm{cm})$ and at least $30 \%$ response by RECIST criteria, at least one-year time span from CRC diagnosis and being listed for transplant. Exclusion criteria as above and including BMI greater than 30. Pre-operative investigations included: PET/CT, CT or MR TAP within four weeks, colonoscopy or CT colonography within 12 months. All patients received tacrolimus converted to sirolimus after four to six weeks, mycofenolate mofetil and corticosteroids.

Liver transplantation technique was not described in detail by any study. Fifty per cent of patients reported by Toso et al. underwent living donor transplantation, while all patients in the SECA-I and SECA-II trials received deceased donor organs. No living or deceased donor details are available.

\section{Patient and primary tumour/metastasis characteristics}

All patients had a primary diagnosis of colorectal adenocarcinoma with non-resectable liver metastases. The patient populations were heterogeneous both within and between studies. Baseline demographics, primary and metastatic disease details and treatment prior to LT are presented in Table 1. The median age was 56, 56 and 59 years. The colon was the most common site of primary tumour in all studies. The percentage of cases that were node positive at the time of diagnosis was $33.3-58.3 \%$ 
Fig. 1 PRISMA flow diagram
Fig. 2 Risk of bias summary and graph showing authors' judements about each risk of bias domain for observational studies using the ROBINS-I tool
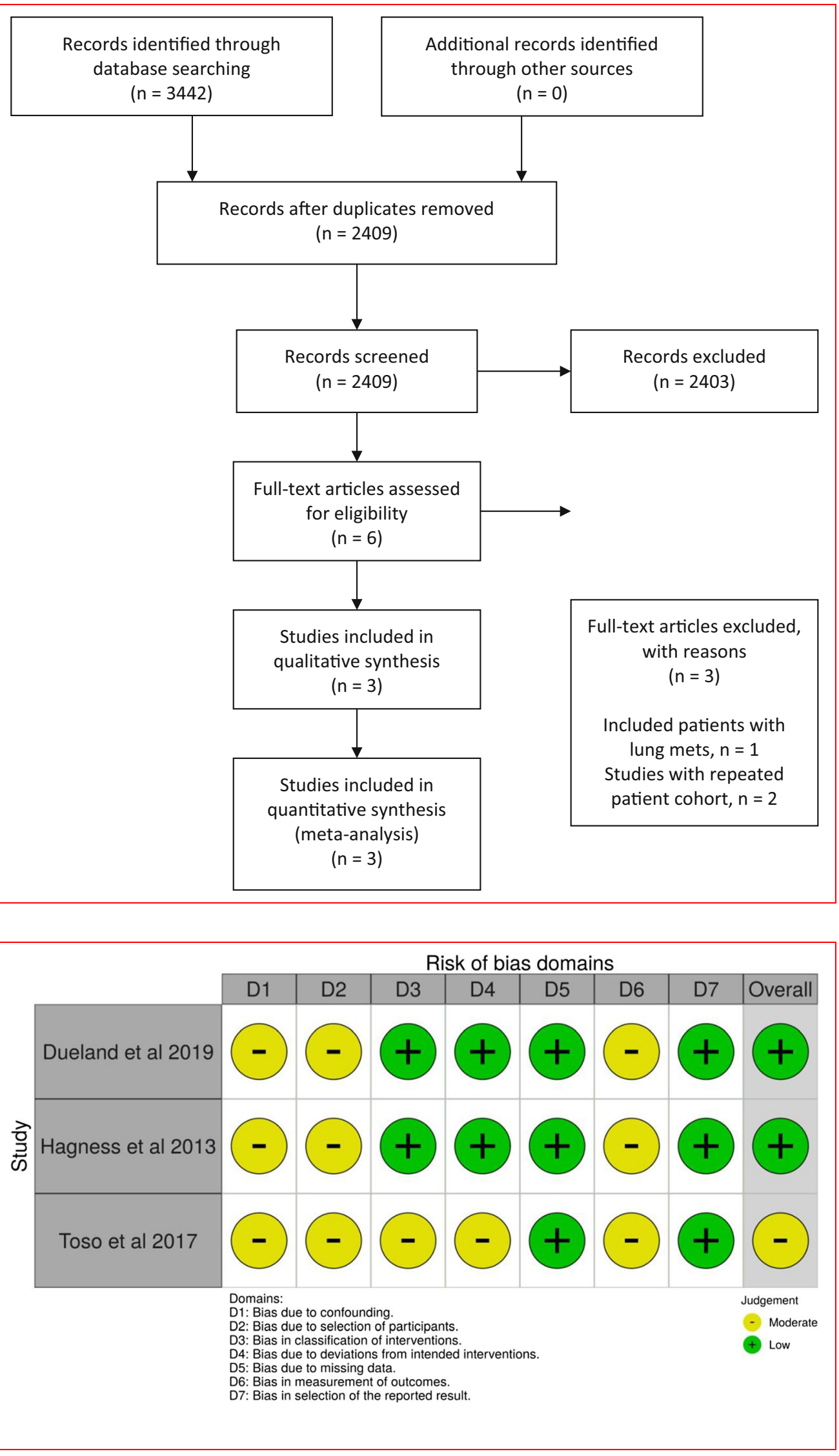
Table 1 Summary of characteristics of included studies

\begin{tabular}{llll}
\hline Study characteristics & $\begin{array}{l}\text { Toso et al. [16]] } \\
\text { Retrospective } \\
\text { Multicentre }\end{array}$ & $\begin{array}{l}\text { Hagness (SECA-I) [17]] } \\
\text { Prospective } \\
\text { Single centre }\end{array}$ & $\begin{array}{l}\text { Dueland (SECA-II) [18]] } \\
\text { Prospective } \\
\text { Single centre } \\
20012-2016\end{array}$ \\
\hline $\mathrm{n}$ & $1995-2015$ & $2006-2011$ & 15 \\
Male:female & 12 & 21 & $8: 7$ \\
Median age (range) & $6: 6$ & $13: 8$ & $59.4(34.9-71.1)$ \\
Performance status, ECOG 0-1 & $56(38-73)$ & $56(45-46)$ & 15 \\
Site of primary Ca: colon, rectum & NR & 21 & 11,4 \\
Node positive at primary diagnosis & 11,1 & 11,10 & $7(46.7 \%)$ \\
Liver metastases $<12$ months from primary diagnosis & $7(58.3 \%)$ & $14(33.3 \%)$ & $14(93.3 \%)$ \\
Median lines of chemotherapy prior to LT (range) & $9(75.0 \%)$ & $17(80.1 \%)$ & $2(1-3)$ \\
Previous liver resection & $2(1-4)$ & $2(1-3)$ & $4(26.7 \%)$ \\
Previous ablation & $10(83.3 \%)$ & $4(19.0 \%)$ & $2(13.3 \%)$ \\
Median months from primary diagnosis to liver metasasis (range) & NR & $2(9.5 \%)$ & $24(13.3-112.2)$ \\
Median months from primary resection to liver metastases (range) & $41(12-97)$ & $36(16-59)$ & NR \\
Median number of metastatic lesions at time of LT (range) & $9(1->15)$ & $8(4-40)$ & $22.6(2.3-111.2)$ \\
Median size of largest lesion at time of LT, mm (range) & $150(10-600) *$ & $45(28-130)$ & $5(1-53)$ \\
Median CEA at LT, unit (range) & $16.9(1-314)$ & $15(1-2002)$ & $24(3-47)$ \\
Median follow up, months (range) & $26(0-108)$ & $27(8-60)$ & $2(1-30)$ \\
\hline
\end{tabular}

ECOG (Eastern cooperative oncology group), LT (liver transplantation), CEA (carcinoembryonic antigen)

and $75.0 \%$. From all studies, $93.3 \%$ had liver metastases confirmed within 12 months of primary diagnosis.

Of note, there was significant heterogeneity in patients who underwent liver resection prior to LT reported by Toso et al. $-83.3 \%$ compared to 26.7 and $19.0 \%$ in the remaining two studies $\left(p=0.0006, I^{2} 86.5 \%\right)$. No significant difference was detected in patients receiving ablation prior to LT $(p=0.92)$. Four out of twelve $(33.3 \%)$ patients received adjuvant chemotherapy following LT compared to none in the SECA-I or SECA-II trials $(p=0.006)$. At the time of LT, the median number of metastatic lesions was 9,8 and 5 with a median size of 150,45 and $24 \mathrm{~mm}$.

\section{Major complications}

All studies reported complications using the Clavien-Dindo (CD) classification system. Major complication rates (CD grades III-V) were $33.3 \%, 47.6 \%$ and $46.7 \%\left(p=0.72, I^{2}\right.$ $0.0 \%)$. No statistically significant difference was found between 30-day mortality rates $\left(p=0.37, I^{2} 0.19 \%\right)$ with only one case of 30-day mortality due to uncontrollable haemorrhage (Fig. 3).

\section{1,3 and 5-year survival}

One-year survival rates were reported as $83.3 \%, 95.2 \%$ and $100.0 \%\left(p=0.22, I^{2} 34.5 \%\right)$. Three-year survival rates were reported at $58.3 \%, 66.7 \%$ and $80.0 \%\left(p=0.48, I^{2}\right.$
$0.0 \%$ ). Five-year survival rates were reported at $50.0 \%$, $61.9 \%$ and $80.0 \%\left(p=0.26, I^{2} 26.1 \%\right)$ (Fig. 3). No statistical significance was detected between studies.

\section{Recurrence, DFS and OS}

One-year DFS was reported as 56\%, 35\% and 53\%, respectively, with the proportion free of recurrence at the end of the studies being $41.7 \%$ (5/12), 9.5\% (2/21) and $53.3 \%(8 / 15)$. The most common site of recurrence in all studies was lung $(5,17$ and 5 acses) followed by liver $(3,7$ and 1 cases). Treatment for recurrence varied within studies and included a range of chemotherapy, radiotherapy and surgical resection. Five out of six deaths reported by Toso et al. were attributable to disease recurrence. In the SECA-I and SECA-II trials, all reported deaths $(n=6,2)$ were due to disease recurrence. DFS and OS Kaplan-Meier curves summarising merged data from all studies are demonstrated in Fig. 3.

\section{Registered trials}

Eight trials for LT in CRLM are registered on clinicaltrials.gov at time of writing spanning six countries (Table 2). Three RCTs plus one study with a randomised element [19-22], three single group assignments [23-25] and two non-randomised trials with parallel trials to be used as comparison groups $[22,26]$. Interventions include living 


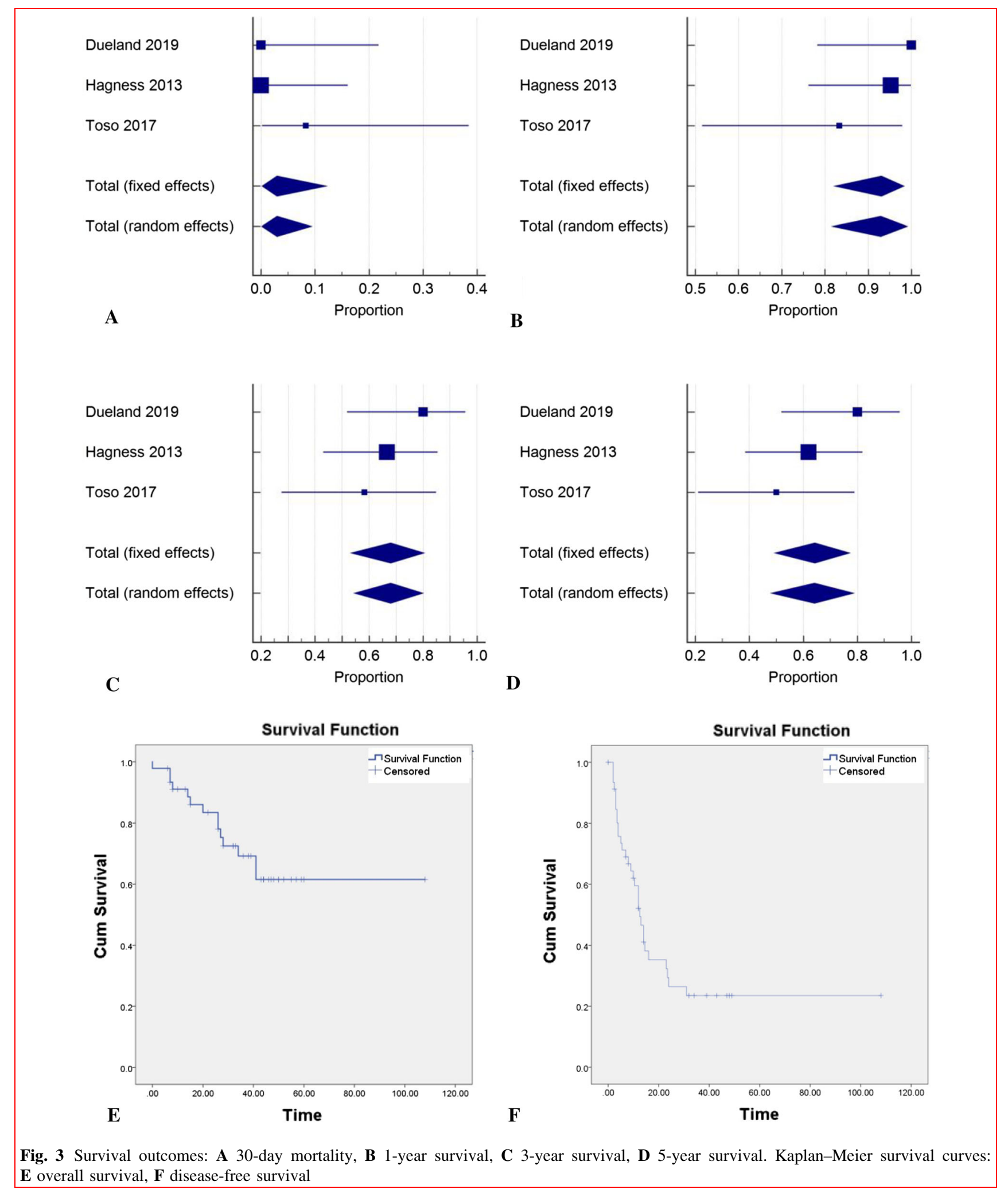

donor (LD) transplantation [23, 24], deceased donor (DD) transplantation [21, 22, 25, 26], extended criteria donor (ECD) transplantation [20] and liver transplantation with staged/delayed hepatectomy [23, 25]. The RCT comparison arms consist of standard chemotherapy regimens or "best alternate care". 
Table 2 Summary of ongoing trials looking at liver transplantation for colorectal liver metastases

\begin{tabular}{|c|c|c|c|c|c|c|c|}
\hline Trial identifier & Country & Study Design & Intervention & $\begin{array}{l}\text { Estimated } \\
\text { enrolment }\end{array}$ & $\begin{array}{l}\text { Start } \\
\text { date }\end{array}$ & $\begin{array}{l}\text { Estimated } \\
\text { end date }\end{array}$ & Primary outcome \\
\hline NCT02597348(22) & France & $\begin{array}{l}\text { RCT } \\
\text { Multicentre }\end{array}$ & $\begin{array}{l}\text { LT preceded by non- } \\
\text { experimental standard } \\
\text { chemotherapy }\end{array}$ & 90 & 2015 & 2027 & $\begin{array}{l}5 \text { year overall } \\
\text { survival }\end{array}$ \\
\hline NCT03488953(26) & Germany & $\begin{array}{l}\text { Single group } \\
\text { assignment } \\
\text { Multicentre }\end{array}$ & $\begin{array}{l}\text { Living donor liver transplant } \\
\text { with } 2 \text { stage hepatectomy }\end{array}$ & 40 & 2018 & 2023 & $\begin{array}{l}3 \text { year overall } \\
\text { survival post } \\
\text { second stage } \\
\text { hepatectomy }\end{array}$ \\
\hline NCT04161092(23) & Sweden & RCT\#Multicentre & $\begin{array}{l}\text { Extended criteria donor } \\
\text { LT + 'best alternate care' }\end{array}$ & 45 & 2020 & 2029 & $\begin{array}{l}5 \text { year overall } \\
\text { survival }\end{array}$ \\
\hline NCT02864485(27) & Canada & $\begin{array}{l}\text { Single group } \\
\text { assignment } \\
\text { Single centre }\end{array}$ & $\begin{array}{l}\text { Live donor LT }+ \text { standard } \\
\text { chemotherapy regime }\end{array}$ & 20 & 2016 & 2023 & $\begin{array}{l}5 \text { year overall } \\
\text { survival, } 5 \text { year } \\
\text { DFS }\end{array}$ \\
\hline NCT01479608(25) & Norway & $\begin{array}{l}\text { Non-randomised, } \\
\text { parallel } \\
\text { assignment } \\
\text { (some } \\
\text { randomisation } \\
\text { open-label) } \\
\text { Single centre }\end{array}$ & $\begin{array}{l}\text { 1. LT vs liver resection } 1: 1 \\
\text { randomisation. } 2 \text {. LT for } \\
\text { NRCLM (metachronus). } 3 \text {. } \\
\text { LT for NRCLM } \\
\text { (synchronous). } 4 \text {. LT for } \\
\text { NRCLM (synchronous) with } \\
\text { expected overall survival } \\
\text { 6-12 months }\end{array}$ & 25 & 2012 & 2025 & $\begin{array}{l}10 \text { year overall } \\
\text { survival }\end{array}$ \\
\hline NCT03494946(24) & Norway & $\begin{array}{l}\text { RCT } \\
\text { Single centre }\end{array}$ & $\begin{array}{l}\text { LT vs chemoTACE/SIRT or } \\
\text { other available options }\end{array}$ & 30 & 2016 & 2027 & $\begin{array}{l}2 \text { year overall } \\
\text { survival }\end{array}$ \\
\hline NCT03803436(29) & Italy & $\begin{array}{l}\text { Non-randomised, } \\
\text { parallel } \\
\text { assignment } \\
\text { Multicentre }\end{array}$ & $\begin{array}{l}\text { Deceased donor LT (comparison } \\
\text { group will be COLT-eligible } \\
\text { patients who enter TRIPLETE } \\
\text { trial-mFOLFOX } \\
\text { panitumumab) }\end{array}$ & 22 & 2019 & 2024 & $\begin{array}{l}5 \text { year overall } \\
\text { survival }\end{array}$ \\
\hline NCT02215889(28) & Norway & $\begin{array}{l}\text { Single group } \\
\text { assignment } \\
\text { Single centre }\end{array}$ & $\begin{array}{l}\mathrm{LT}+\text { segment } 2 / 3 \\
\quad \text { resection }+ \text { delayed } \\
\text { hepatectomy }\end{array}$ & 20 & 2014 & 2021 & $\begin{array}{l}\text { Percentage of } \\
\text { transplant patients } \\
\text { receiving second } \\
\text { stage hepatectomy } \\
\text { within } 4 \text { weeks }\end{array}$ \\
\hline
\end{tabular}

RCT (randomised control trial), LT (liver transplantation), NRCLM (non-resectable colorectal liver metastases), TACE (transarterial chemoembolization), SIRT (selective internal radiation therapy), DFS (disease-free survival)

\section{Discussion}

Our analysis of 48 patients is likely to have captured the majority of LT carried out for CRLM during this time period; the ELTR reports 53 liver transplants for CRLM carried out from 2001-2016 (13). All included studies are European and only one of the eight trials registered on clinicaltrials.gov is based outside Europe (Canada, NCT02864485 [24]). Despite heterogeneity both within and between study populations, the results appear concordant with each other.

The 5-year survival for all indications of LT is $71 \%$ and has been relatively steady since 2000 [10]. The current five-year survival following LT is $67 \%$ for primary liver tumours and $61 \%$ for metastatic liver disease [10]. The reported five-year survival rates of $50 \%, 61.9 \%$ and $80 \%$ in studies after 1995 show a vast improvement from the $18 \%$ seen prior to 1995-at which time, the rate of graft loss in CRLM patients was as high as $44 \%$ in the absence of tumour recurrence [8] and a series of 25 patients reported a 30-day mortality approaching 30\% [27]. This is consistent with known improvements in LT outcomes due to advancements in surgical technique, better immunosuppressive regimens [28], improvements in the management of advanced colorectal cancer, including chemotherapy regimens [29] and better methods of down-staging tumours [28].

Although the treatment for NRCLM, palliative chemotherapy, has also improved in recent years, the fiveyear survival remains less than $10 \%[4,5]$. The same cohort from the SECA-I trial has been directly compared with a corresponding group from the NORDIC VII trial 
(first line chemotherapy for NRCLM) with five-year survival in the NORDIC VII group of $9 \%$, rising to $19 \%$ when only those with the most favourable tumour and disease characteristics were considered [30]. This remains a significantly lower OS when compared with LT studies.

Despite the promising data regarding OS, there remains a high recurrence rate (44-65\% in the first year) and DFS reduces rapidly during the first two years following transplant for CRLM. Typically DFS is seen as a good surrogate marker for OS in CRC, however despite the early recurrence seen in this study, OS remains relatively high.

Pulmonary recurrence was the most frequent site of recurrence in all studies, a proportion of which may be the result of undetected micrometastases at time of tumour staging. This is due to the lack of diagnostic methods with adequate sensitivity to detect and characterize very small lesions. Following LT, where lung was the first-site of recurrence the 5-year survival was 72\%. 5-year OS from all sites of recurrence was $53 \%$ [31].

Interestingly, growth of pulmonary metastases was relatively slow despite immunosuppression and although OS was poorer compared to those without pulmonary metastases, OS remained greater than when compared with outcomes after palliative chemotherapy [32]. We suggest that the link between DFS and OS should be interpreted with caution in the setting of LT for CRLM in upcoming trials, particularly in pulmonary recurrence.

Given the extrahepatic nature of the majority of metastases, control of systemic disease is an important factor. All patients received neo-adjuvant chemotherapy, however of the 48 patients, only four (8.3\%) received adjuvant chemotherapy following LT, unfortunately individual outcome data was not reported. Adjuvant chemotherapy following resection of liver metastases has been shown to improve OS [33], however, the side effects of chemotherapy may be exacerbated by immunosuppression [34] and certain chemotherapeutic agents have the potential to increase the risk of rejection [35]. Adjuvant chemotherapy would treat any undetected micrometastases and circulating tumour cells to prevent seeding. Further investigation is required to establish efficacy and safety in this setting, however none of the currently registered trials clearly report the use of adjuvant chemotherapy.

To determine the true impact of disease recurrence and define the relationship between DFS and OS, the publication of long-term survival data is necessary. It is known that the 10-year survival for LT for NET is $46.1 \%$ for isolated liver metastases [36] and $12-36 \%$ for those who have undergone liver resection for CRLM [37]. It will be interesting to see how this will compare to those who have undergone LT for CRLM.

The apparent improvement in the first five years following LT reported between the SECA-I and SECA-II trials could be explained in part by refined patient selection. The SECA-I trial identified 4 factors: pre-transplant tumour diameter $>5.5 \mathrm{~cm}$ (high hepatic tumour load), CEA before $\mathrm{LT}>80 \mathrm{ug} / \mathrm{L}$, disease progression on chemotherapy and short interval from primary resection to transplant [17]. Although the association of 5-year survival with tumour size was not seen by Toso et al. [16], these factors are consistent with known poor prognostic indicators, including following R0 resection, of CRLM [6, 38].

Scoring systems used to predict recurrence after CRLM resection, such as the Fong Clinical Risk Score (FCRS) [39] or the Oslo Score, proposed by the Norwegian group to identify patients at risk of recurrence after LT, are both based on the above factors and could be used to aid patient selection to obtain survival rates comparable with other indications for LT [40].

The commonality of these factors are all indicative of an aggressive tumour biology-rather than the technical factors which make a tumour unresectable. Patients with a high hepatic tumour load who underwent LT for NRCLM were matched to a group who had resectable disease and who underwent portal vein embolization plus liver resection. OS was significantly higher in the LT group which may indicate that technically resectable patients may also benefit from transplantation, an area which needs further research [41].

Given the scarcity of resources, defining the patient population who will most benefit from liver transplantation is a key step and refinement of prognostic indicators in coming trials could aid decision-making when national graft allocation is considered. It has been argued that with strict criteria, only a very small subset of patients with NRCLM will be eligible for transplantation; the SECA-II trial recruited 15 patients over five years from a catchment area with a population of five million [18] which would expand if resectable patients were also considered.

To address this, trials are looking at living donation (NCT03488953 [23], NCT02864485 [24]) and extended criteria donors (NCT04161092 [20]) as a way to expand the donor pool. Currently living donors account for just $2-3 \%$ of donors for primary and secondary liver malignancies [36]. Reported outcomes for ECD (an arm of the SECA II trial) had a shorter DFS and worse OS compared to those who underwent standard graft transplantation, however they had more advanced disease. 1/10 was retransplanted for graft failure [42]. A small case series in South Africa has used ECD with patients who meet the SECA I inclusion criteria with an $80 \%$ (4/5) survival (death due to recurrent disease) with a median follow up of 38 months and a $100 \%(5 / 5)$ recurrence rate with a median recurrence of six months [43]. No trials are currently looking into those with technically resectable disease. 
Much of the literature published in recent years has come out of Oslo, Norway, where the deceased donor pool is relatively large with a short transplant waiting list. If the currently registered trials hit their enrollment targets, the data for nearly 300 further patients will become available over the next 10 years, however this may still leave some matters unaddressed.

\section{Conclusion}

Although current evidence suggests a survival benefit conferred by LT in NRCLM, the ethical implications of organ availability and allocation demand rigorous justification. The current evidence is encouraging but refers to a small patient population. Larger randomized studies with more longitudinal data are needed and the refinement of patient selection is critical to improve DFS and OS. Concomitant improvements in the management of patients following liver resection and of palliative chemotherapy regimens is paramount.

Funding Open Access funding provided by the IReL Consortium. No funding was received for this study.

\section{Declarations}

Conflict of interest The authors declare that they have no conflict of interest.

Open Access This article is licensed under a Creative Commons Attribution 4.0 International License, which permits use, sharing, adaptation, distribution and reproduction in any medium or format, as long as you give appropriate credit to the original author(s) and the source, provide a link to the Creative Commons licence, and indicate if changes were made. The images or other third party material in this article are included in the article's Creative Commons licence, unless indicated otherwise in a credit line to the material. If material is not included in the article's Creative Commons licence and your intended use is not permitted by statutory regulation or exceeds the permitted use, you will need to obtain permission directly from the copyright holder. To view a copy of this licence, visit http://creativecommons. org/licenses/by/4.0/.

\section{References}

1. Ferlay J, Soerjomataram I, Dikshit R, Eser S, Mathers C, Rebelo $M$ et al (2015) Cancer incidence and mortality worldwide: sources, methods and major patterns in GLOBOCAN 2012. Int J Cancer 136(5):E359-E386

2. Manfredi S, Lepage C, Hatem C, Coatmeur O, Faivre J, Bouvier AM (2006) Epidemiology and management of liver metastases from colorectal cancer. Ann Surg 244(2):254-259

3. Siegel RL, Miller KD, Jemal A (2017) Colorectal Cancer Mortality Rates in Adults Aged 20 to 54 Years in the United States, 1970-2014. JAMA 318(6):572-574
4. Engstrand J, Nilsson H, Strömberg C, Jonas E, Freedman J (2018) Colorectal cancer liver metastases-a population-based study on incidence, management and survival. BMC Cancer 18(1):78

5. Sanoff HK, Sargent DJ, Campbell ME, Morton RF, Fuchs CS, Ramanathan RK et al (2008) Five-year data and prognostic factor analysis of oxaliplatin and irinotecan combinations for advanced colorectal cancer: N9741. J Clin Oncol 26(35):5721-5727

6. Kanas GP, Taylor A, Primrose JN, Langeberg WJ, Kelsh MA, Mowat FS et al (2012) Survival after liver resection in metastatic colorectal cancer: review and meta-analysis of prognostic factors. Clin Epidemiol 4:283-301

7. Hoti E, Adam R (2008) Liver transplantation for primary and metastatic liver cancers. Transpl Int 21(12):1107-1117

8. Registry ELT. Data analysis booklet, Paris 2007 [Available from: http://www.eltr.org.

9. Adam R, Karam V, Delvart V, O'Grady J, Mirza D, Klempnauer J et al (2012) Evolution of indications and results of liver transplantation in Europe. A report from the European Liver Transplant Registry (ELTR). J Hepatol 57(3):675-688

10. Adam R, Karam V, Cailliez V, O’Grady JG, Mirza D, Cherqui D et al (2018) Annual Report of the European Liver Transplant Registry (ELTR)-50-year evolution of liver transplantation. Transpl Int 31(12):1293-1317

11. Zamora-Valdes D, Leal-Leyte P, Kim PT, Testa G (2017) Fighting mortality in the waiting list: liver transplantation in north America, Europe, and Asia. Ann Hepatol 16(4):480-486

12. Ouzzani M, Hammady H, Fedorowicz Z, Elmagarmid A (2016) Rayyan-a web and mobile app for systematic reviews. Syst Rev 5(1):210

13. Review Manager (RevMan) Version 5.3 ed. Copenhagen: The Nordic Cochrane Centre: The Cochrane Collaboration; 2014.

14. Freeman MF, Tukey JW (1950) Transformations related to the angular and the square root. Ann Math Statist 21(4):607-611

15. DerSimonian R, Laird N (1986) Meta-analysis in clinical trials. Control Clin Trials 7(3):177-188

16. Toso C, Pinto Marques H, Andres A, Castro Sousa F, Adam R, Kalil A et al (2017) Liver transplantation for colorectal liver metastasis: Survival without recurrence can be achieved. Liver Transpl 23(8):1073-1076

17. Hagness M, Foss A, Line PD, Scholz T, Jørgensen PF, Fosby B et al (2013) Liver transplantation for nonresectable liver metastases from colorectal cancer. Ann Surg 257(5):800-806

18. Dueland S, Syversveen T, Solheim JM, Solberg S, Grut H, Bjørnbeth BA et al (2020) Survival following liver transplantation for patients with nonresectable liver-only colorectal metastases. Ann Surg 271(2):212-218

19. Adam R. Liver Transplantation in Patients With Unresectable Colorectal Liver Metastases Treated by Chemotherapy Available from: https://ClinicalTrials.gov/show/NCT02597348

20. Lindner PG. The Swedish Study of Liver Transplantation for Non-resectable Colorectal Cancer Metastases Available from: https://ClinicalTrials.gov/show/NCT04161092

21. Dueland S. Liver Transplantation Compared to Chemotherapy in Patients With ColoRectal Cancer Available from: https://Clin icalTrials.gov/show/NCT03494946

22. Dueland S. A Randomized Controlled Clinical Trial to Evaluate the Benefit and Efficacy of Liver Transplantation as Treatment for Selected Patients With Liver Metastases From ColoRectal Carcinoma Available from: https://ClinicalTrials.gov/show/ NCT01479608

23. Rauchfuß F. Living Donor Liver Transplantation With Two Stage Hepatectomy for Patients With Isolated, Irresectable Colorectal Liver Metastases Available from: https://ClinicalTrials.gov/show/ NCT03488953 
24. Sapisochin G. Living Donor Liver Transplantation for Unresectable Colorectal Cancer Liver Metastases Available from: https://ClinicalTrials.gov/show/NCT02864485

25. Dueland S. Partial Liver Segment 2/3 Transplantation Study Available from: https://ClinicalTrials.gov/show/NCT02215889

26. Mazzaferro V. Improving Outcome of Selected Patients With Non-resectable Hepatic Metastases From Colo-rectal Cancer With Liver Transplantation Available from: https://ClinicalTrials. gov/show/NCT03803436

27. Mühlbacher F, Huk I, Steininger R, Gnant M, Götzinger P, Wamser P et al (1991) Is orthotopic liver transplantation a feasible treatment for secondary cancer of the liver? Transplant Proc 23(1 Pt 2):1567-1568

28. Yang Z, Wang Y, Ye Q (2019) Liver Transplantation for Progressive Unresectable Colorectal Liver Metastases: Case Report and Review of the Literature. Transplant Proc 51(9):3124-3130

29. Claassen YH, van der Valk MJ, Breugom AJ, Frouws MA, Bastiaannet E, Liefers GJ et al (2018) Survival differences with immediate versus delayed chemotherapy for asymptomatic incurable metastatic colorectal cancer. Cochrane Database Syst Rev 11:CD012326

30. Dueland S, Guren TK, Hagness M, Glimelius B, Line PD, Pfeiffer P et al (2015) Chemotherapy or liver transplantation for nonresectable liver metastases from colorectal cancer? Ann Surg 261(5):956-960

31. Hagness M, Foss A, Egge TS, Dueland S (2014) Patterns of recurrence after liver transplantation for nonresectable liver metastases from colorectal cancer. Ann Surg Oncol 21(4):1323-1329

32. Grut H, Solberg S, Seierstad T, Revheim ME, Egge TS, Larsen SG et al (2018) Growth rates of pulmonary metastases after liver transplantation for unresectable colorectal liver metastases. Br J Surg 105(3):295-301

33. Krishnamurthy A, Kankesan J, Wei X, Nanji S, Biagi JJ, Booth CM (2017) Chemotherapy delivery for resected colorectal cancer liver metastases: Management and outcomes in routine clinical practice. Eur J Surg Oncol 43(2):364-371

34. Kim R, Tan A, Estfan B, Aucejo F (2009) Adjuvant treatment after orthotopic liver transplantation: is it really necessary? Oncology (Williston Park) 23(14):1276-1281
35. Krisl JC, Doan VP (2017) Chemotherapy and transplantation: the role of immunosuppression in malignancy and a review of antineoplastic agents in solid organ transplant recipients. Am J Transplant 17(8):1974-1991

36. Valvi D, Mei X, Gupta M, Shah MB, Ancheta A, Marti F et al (2021) Younger age is associated with improved survival in patients undergoing liver transplantation alone for metastatic neuroendocrine tumors. J Gastrointest Surg. 25(6):1487-1493

37. Abbas S, Lam V, Hollands M (2011) Ten-year survival after liver resection for colorectal metastases: systematic review and metaanalysis. ISRN Oncol. 2011:763245

38. Petrelli F, Coinu A, Zaniboni A, Pietrantonio F, Barni S (2016) Prognostic factors after R0 resection of colorectal cancer liver metastases: A systematic review and pooled-analysis. Rev Recent Clin Trials 11(1):56-62

39. Fong Y, Fortner J, Sun RL, Brennan MF, Blumgart LH (1999) Clinical score for predicting recurrence after hepatic resection for metastatic colorectal cancer: analysis of 1001 consecutive cases. Ann Surg 230(3):309-318

40. Dueland S, Grut H, Syversveen T, Hagness M, Line PD (2020) Selection criteria related to long-term survival following liver transplantation for colorectal liver metastasis. Am J Transplant 20(2):530-537

41. Dueland S, Yaqub S, Syversveen T, Carling U, Hagness M, Brudvik K et al (2021) Survival outcomes after portal vein embolisation and liver resection compared with liver transplant for patients with extensive colorectal cancer liver metastases. JAMA Surg 156(6):550-557

42. Smedman TM, Line PD, Hagness M, Syversveen T, Grut H, Dueland S (2020) Liver transplantation for unresectable colorectal liver metastases in patients and donors with extended criteria (SECA-II arm D study). BJS Open 4(3):467-477

43. Botha J, Demetriou G, Fabian J, Etheredge H (2020) Liver transplant for nonresectable colorectal cancer liver metastases in South Africa: a single-center case series. Exp Clin Transplant. 18(7):842-846

Publisher's Note Springer Nature remains neutral with regard to jurisdictional claims in published maps and institutional affiliations. 